\title{
Postgraduate mathematics education students' experiences of using digital platforms for learning within the COVID-19 pandemic era
}

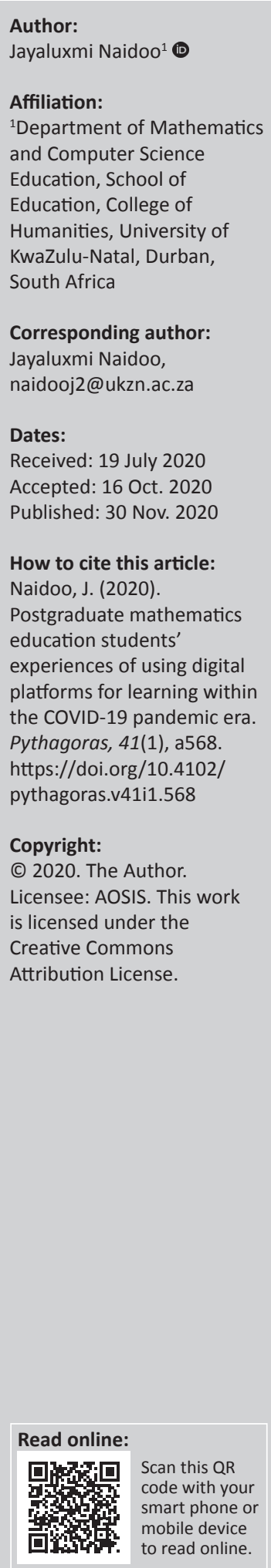

Within the digital era, as global society embraces the fourth industrial revolution, technology is being integrated swiftly within teaching and learning. Within the Coronavirus disease (COVID-19) pandemic era, education institutions are preparing robustly for digital pedagogy. This article reports on a study focusing on 31 postgraduate mathematics education students' experiences of using digital platforms for learning during the COVID-19 pandemic era. The study was located at one teacher education institution in KwaZulu-Natal, South Africa. The research process encompassed three interactive online workshops and two online discussion forums, which were conducted via different digital platforms (Zoom, Moodle and WhatsApp). The study was framed using the theory of Communities of Practice, which denotes a group of people who share an interest which is enhanced as group members support and interact with each other. Qualitative data generated during the interactive online workshops and discussion forums were analysed thematically. The results exhibit challenges and strengths of using digital platforms as experienced by the participants. The results of this study suggest that before using digital platforms for mathematics learning, it is important for students to be encouraged to practise and engage collaboratively within digital platforms. The study adds to the developing knowledge in the field concerning using digital platforms for learning mathematics within the COVID-19 pandemic era.

Keywords: COVID-19; digital platform; fourth industrial revolution; mathematics; Moodle; technology; WhatsApp; Zoom.

\section{Introduction}

Technology is increasingly used by society in education, business and general daily activities (Bell, 2011; Qurat-ul et al., 2019). Also, as we embrace, the fourth industrial revolution (4IR), there are various debates on how existing educational contexts can be adapted to support and incorporate the use of technology-based tools. Technology-based tools in this study refers to electronic, digital or any other teaching tools that are supported by technology and are used within educational contexts to facilitate learning (Ertmer \& Ottenbreit-Leftwich, 2012). Within the context of this study, digital platforms provided the participants and the lecturer with a diverse array of technology-based tools for communicating and attaining new knowledge and skills to enhance and guide the online learning process. Also, within this study, digital platforms and web-based resources were used with computers or mobile gadgets which supported pedagogy using text, audio and video (Peachey, 2017). Thus, digital platforms assisted the online community of practice (participating postgraduate mathematics education students) in using digital resources and engaging with learning materials online. These platforms are combined software solutions which supported online learning within this study.

Moreover, the Coronavirus disease (COVID-19) pandemic has transformed life resulting in social and educational lockdowns globally and within the era of the 4IR. Considering the novel COVID-19 pandemic conditions, higher education institutions are inclining towards using digital tools to support digital pedagogy. Digital pedagogy, which is a strategy for teaching and learning using digital platforms, is seen as a technique to avoid the spread of the contagious COVID-19 virus (Murgatrotd, 2020).

Also, the contemporary 4IR education contexts support pedagogy that encourages critical thinking, hands-on learning, collaboration, problem-solving approaches, the use of digital platforms and technology-based pedagogy (Goertz, 2015). Thus, technology within the 4IR education context is significant to improve the digital education setting (Boholano, 2017; Klopfer, 
Osterweil, Groff, \& Haas, 2006). Digital education settings support the effective integration of technology-based tools (for example, computers and mobile devices) for teaching and learning (Buzzard, Crittenden, Crittenden, \& McCarty, 2011). This study aimed to respond to the main research question: what are postgraduate mathematics education students' experiences of using digital platforms for learning within the COVID-19 pandemic era?

\section{Fourth industrial revolution}

The 4IR comprises various methods of integrating technology within societies and human bodies (Schwab, 2016). Within the 4IR era, technology-based tools and digital platforms are transforming the way we conduct our lives. This transformation is unsettling society since the 4IR has changed the way nations subsist and is epitomised by blending the virtual and physical domains (Schwab, 2016), shaping a comprehensively linked and progressive society.

Students may be at different levels concerning readiness for progressing within the 4IR: students may be digital natives or digital immigrants. Digital natives are acquainted with the use of technology-based tools and digital platforms (for example, the Internet, computers and other online tools or platforms). The term is generally used to characterise students who are familiar with technology-based tools (Helsper \& Enyon, 2009). These students will probably succeed when using technology-based tools and digital platforms when learning. In contrast, digital immigrants are students who may acquire the knowledge of how to use technology-based tools, but rather than working online initially, they may examine printed information first before referring to the Internet for support (Helsper \& Enyon, 2009). These students may need added assistance when using technology-based tools and digital platforms. As is evident, lecturers need to be aware of their students' abilities concerning their acquaintance of using technology-based tools and digital platforms when learning. This knowledge will support the lecturer when presenting the notions of the 4IR within the education environment.

Also, education institutions need to adjust to prepare students sufficiently to thrive within these circumstances (Butler-Adam, 2018; Mensch, 2017; Schieffer, 2016; Thieman, 2008). The 4IR impacts the purpose that higher education institutions play in preparing students for succeeding within our technologically advanced society. To take advantage of 4IR opportunities, more so within the era of the COVID-19 pandemic, we need to transform our pedagogy to include the successful use of technology-based tools and digital platforms.

\section{Using digital platforms and technology in mathematics teaching and learning}

The digital world has changed education environments, and teaching and learning are being transformed through using technology-based teaching tools (Grand-Clement, Devaux,
Belanger, \& Manville, 2017; Jeffrey, Milne, Suddaby, \& Higgins, 2014; Lazarus \& Roulet, 2013). Integrating technology in mathematics pedagogy supports teaching and learning and has positive effects on student performance (Cheung \& Slavin, 2013; Mlotshwa \& Chigona, 2018). However, within South Africa, mathematics teachers' use of technology-based tools for teaching and learning is negatively affected by their lack of computer skills. Thus, many mathematics teachers are hesitant to transform their pedagogy to incorporate the use of technology within their classrooms (Stols et al., 2015). Nevertheless, there are many online mathematics teaching and learning websites and several educational applications that can influence students' learning and achievement (Pope \& Mayorga, 2019). This online teaching and learning support is available for mathematics teachers to engage with since student performance in mathematics has been improved through using digital tools for teaching (Cheung \& Slavin, 2013). In the study conducted by Cheung and Slavin (2013), the authors focused on researching the link between mathematics achievement and the use of technology. Also, that study focused on exploring computer management learning and is therefore related to this study. Computer management learning is similar to Moodle, which is a learning management system (LMS) being used at the participating university in the study under focus.

The use of Moodle in the teaching and learning of mathematics within higher education supports students' learning (Lopes, Babo, \& Azevedo, 2008) by stimulating students' interest which results in a positive effect on student performance (Handayanto, Supandi, \& Ariyanto, 2018). Moreover, the use of digital platforms, for example Moodle, results in an improvement in students' performance in mathematics (Jayashree \& Tiwari, 2016). Also, successful mathematics students and those that have challenges may benefit from the use of digital tools (Bruce, 2012) since the use of technologybased tools in mathematics has shown a positive link with student achievement (Cheung \& Slavin, 2013). Furthermore, the implementation of digital platforms for the learning of mathematics encourages supportive relationships to be developed within communities of practice (Mlotshwa \& Chigona, 2018). However, it is also important to note that the success of using digital tools also depends on the design of the digital tools and platforms as well as the time allocated for completing specific content within the curriculum (Drijvers, 2013; Sahal \& Ozdemir, 2020). Moreover, the use of digital tools in teaching and learning can lead to students becoming easily distracted, and as a result they may not complete their academic work timeously (Mbukusa, 2018).

Therefore, it is dependent on the mathematics teacher to select the most helpful digital tool to achieve the full potential of digital pedagogy to support students' learning. Thus, it is the teacher's responsibility to enable progression in education (Montrieux, Vanderlinde, Schellens, \& De Marez, 2015). Especially within the current COVID-19 pandemic era, the use of digital platforms to support pedagogy within the 4IR 
is essential. Some of these digital platforms used at the participating university include Zoom ${ }^{1}$, WhatsApp ${ }^{2}$ and Moodle ${ }^{3}$.

Thus, the digital world has entered education spheres, with digital devices and platforms being used to deliver education (Grand-Clement et al., 2017). Given the ubiquity of smartphone technology and the ease with which it is used in daily life, excluding smartphones from higher education courses confines prospects for these courses to be contemporary and realistic (Schuck, 2016). To ensure that courses and pedagogy are current and realistic, many higher education institutions are advancing to integrate digital devices and digital platforms (for example tablet computers, laptops, smartphones, netbooks, social media, Zoom, Google Meet, Microsoft Teams, Google Drive and Google Classroom) within pedagogy.

\section{Theoretical framing: Communities of Practice}

This study was framed using Wenger's (1998) Communities of Practice (COP) theory, a theory of learning that has its own set of norms and emphasis in which the fundamental unit of analysis is the COP (Graven \& Lerman, 2003). A COP revolves around events that are of interest to members of that community (Wenger, 1998). A COP may create an environment of thinking, insight and responses that supports the connection between researchers and practitioners such that the information generated is more valued and substantial (Hearn \& White, 2009).

Wenger's (1998, p. 4) COP theory is founded on four principles: individuals are social beings, information concerns 'valued enterprises', knowing is about participation and experiences in the world and meaning is what learning produces. This theory maintains that a COP is formed by people who partake in the activity of communal learning within a public space. Thus, a COP comprises groups of people who share an interest in something, and through cooperation they learn how to advance what they adopt (Wenger \& Wenger-Trayner, 2015). Furthermore, within the COP theory, learning is identified as being made up of four elements: practice, meaning, identity and community (Wenger, 1998).

The relationship between this study and the COP theory is clarified as follows: a COP shares an interest; within the scope of this research the shared area of interest was the use of digital platforms for the learning of mathematics. Within the ambits of COP, members of the community partake in the activity of communal learning. Since technology can surpass

1.Zoom is a video conferencing software application that allows you to interact virtually with friends, colleagues, students and family when face-to-face communication is not possible. Zoom is a digital platform used for teaching and learning at the participating university during the COVID-19 pandemic.

2.WhatsApp is a free messenger application that uses the Internet to send and receive messages and calls. WhatsApp was used unofficially at the participating university by lecturers and students as a digital platform to communicate via messages, images, audio and video files during the COVID-19 pandemic.

3.Moodle is a learning management system used at the participating university. It is an open-source e-learning digital platform. location and time, virtual COPs, which rely primarily on technology to connect the online COP, are becoming increasingly popular (Dubé, Bourhis, \& Jacob, 2006). Within the domains of this study, shared learning within the virtual COP took place via three interactive online workshops and two discussion forums.

Thus, within the ambits of a virtual COP, members of the COP in this study were the postgraduate mathematics education students and the mathematics lecturer. The postgraduate mathematics education students in this study were also practising mathematics teachers at school level. The researcher was the mathematics lecturer who taught these participants at the research site. A virtual COP may use traditional tools, for example a telephone, and more advanced technological tools, such as emails, cell phones, virtual meeting spaces, digital platforms and websites, to create a shared virtual collaborative space (Dubé et al., 2006). The virtual COP under study supported each other as they interacted within the interactive workshops and online discussion forums; they shared resources online and discussed challenges with the mathematics content being discussed. The learning process was collaborative and interactive (Osterholt \& Barratt, 2010), which involved all members of the virtual COP. Thus, this theoretical framework provided the framing for this study which focused on one main research question: what are postgraduate mathematics education students' experiences of using digital platforms for learning within the COVID-19 pandemic era?

\section{Research methods and design General background}

This qualitative study, which aimed to explore postgraduate mathematics education students' experiences of using digital platforms for learning, was located within an interpretive paradigm. Data were generated via three interactive online workshops and two discussion forums at one teacher education institution in KwaZulu-Natal, South Africa. The participating university's research committee approved gatekeeper access and ethical clearance. The study incorporated three interactive online workshops and two online discussion forums with participants. The participants were purposively selected for convenience since the researcher taught these participants.

\section{Participants}

Participants were emailed an informed consent sheet outlining the purpose and process of the study; the participants' right to leave the study without prejudice was also noted on the informed consent sheet. Pseudonyms were used to protect the anonymity and confidentiality of participants. Forty-two postgraduate mathematics education students were invited to participate in the study, and 37 agreed to participate in the study (23 male and 14 female). Six participants were selected at random to join the pilot study. Hence, the remaining 31 postgraduate mathematics 
education students, who were also practising mathematics school teachers, participated in the main study.

\section{Pilot study}

The pilot study was conducted with six participants who were part of the postgraduate mathematics education class. These participants were randomly selected and were not included in the sample for the main study. All interactive workshops were piloted; during the pilot study, Internet connections were limited, sluggish and unsteady since the workshops were conducted at peak times when Internet service providers were supplying numerous customers which led to slow network speed and unstable networks. Hence, the workshops took longer than anticipated. Also, during the pilot, individual participants were unclear about what was required of them for the discussion forum questions. To avoid similar issues during the main study, through negotiation with the participating postgraduate mathematics education students, the online workshops were held at off-peak times to ensure the speed and steadiness of Internet networks. Also, the online discussion forums were piloted to explore the learning of mathematics by using digital platforms as experienced by the participants of the pilot study. As a result of conducting the pilot study, the questions used during the workshops and discussion forums were revised to enhance the trustworthiness of the research instruments and process. Thus, by conducting the pilot workshops and piloting the discussion forums, the consistency and dependability of the study were maintained. This was important for ensuring that the results were due to the study itself and not as a consequence of any other peripheral factors.

\section{Main study}

Thirty-one postgraduate mathematics education students agreed to participate in the main study. Data were generated via three interactive online workshops and two online discussion forums. Although 31 participants were involved in the workshops, due to various reasons, only 15 participants (eight male and seven female) were available to take part in the discussion forums. To assure the participants of their anonymity, pseudonyms were used. Table 1 represents the pseudonyms used for the participants in the discussion forums.

\section{Online workshops}

The purpose of the interactive workshops was to explore postgraduate mathematics education students' experiences of using digital platforms within the COVID-19 pandemic era. A sequence of online mathematics workshops $(N=3)$ via Zoom (a digital platform used at the participating university) was held. These workshops were facilitated by the lecturer, who is also the researcher. These workshops were mandatory and were part of a postgraduate Mathematics Education module for which the participants were registered. All participants were provided with notes, PowerPoint
TABLE 1: The 15 postgraduate mathematics education students who participated in the discussion forums.

\begin{tabular}{ll}
\hline Participant number & Pseudonym \\
\hline 1 & John \\
2 & Thulani \\
3 & Siya \\
4 & Kavir \\
5 & Leon \\
6 & Delani \\
7 & Xolani \\
8 & Patrick \\
9 & Nancy \\
10 & Anne \\
11 & Devi \\
12 & Rani \\
13 & Thandi \\
14 & Nomsa \\
15 & Lungi \\
\hline
\end{tabular}

presentations of case studies, and examples of online assessments focusing on using digital tools and free online websites within a digital mathematics education environment. Within this environment, the lecturer presented the module content and shared resources with the participants online via email, Zoom chats and Moodle. The content for the first workshop focused on academic writing, and the second workshop concentrated on assessing and providing feedback for algebra. The third workshop was dedicated to identifying school learners' misconceptions in geometry. At the end of the third workshop, all participants were invited to participate in two discussion forums (using WhatsApp and Moodle digital platforms). The researcher presented content for all three workshops, and the postgraduate mathematics education students engaged with and discussed the content that was introduced with members of the virtual COP. The discussion forums were not compulsory.

\section{Online discussion forums}

The purpose of the two discussion forums was to explore postgraduate mathematics education students' experiences of using digital platforms for the learning of mathematics. The discussion forums were conducted online using digital platforms, for example Moodle and WhatsApp chats. Questions were placed on these digital platforms, and the participants had one week to respond to questions posed. If further probing was required for clarification purposes, the researcher would ask specific participants follow-up questions in each discussion forum. Each discussion forum began with a few general questions to place the participants at ease. The discussion forum then progressed to specific items focusing on the participating postgraduate mathematics education students' experiences of using digital platforms for learning about mathematics academic writing, learning how to assess and provide learners with feedback for mathematics problems in algebra as well as how to identify learner misconceptions in geometry.

During the explanation of the research process, participants were asked to respond at least once to each question posed 
during the discussion forums. The discussion forums focused on the following key questions:

- What were the postgraduate mathematics education students' experiences of using digital platforms for learning?

- What were the strengths of using digital platforms for the learning of mathematics?

- What were the challenges of using digital platforms for the learning of mathematics?

The discussion forums were recorded; transcriptions of the discussion forums were sent to each participant for perusal to ensure the correctness of the information captured within these forums.

\section{Data analysis}

Data analysis in the form of coding and categorising of themes was based on the conceptual framework of the study, that is, COP theory. The relationship between the data generated and the notions of practice, meaning, identity and community (Wenger, 1998) were examined. Data analysis included the following steps: firstly, open coding was used to ensure acquaintance with the data and to classify codes after inspecting the qualitative data; secondly, all data were perused, and codes were processed into themes. The data that were related to each other were grouped into themes. Thirdly, the themes were scrutinised to ensure that all codes within each theme revealed a connection. Finally, the similarities and difference between the participants' responses were compared, and subthemes were identified. Also, to confirm the accuracy of results and to provide participants with the chance to clarify their responses, member checking was undertaken.

\section{Ethical consideration}

Ethical clearance for this study was obtained from the Ethics Committee of the participating university. The participants were assured that pseudonyms would be used to ensure and protect their confidentiality and anonymity when using all generated data. Participants provided informed consent to participate in the study, noting that they allowed the use of their responses to the online workshops and discussion forums for research purposes. Ethical clearance number: HSS/1562/016.

\section{Results}

Postgraduate mathematics education students had various experiences when using digital platforms for learning. These experiences are presented in themes and subthemes that follow.

\section{Strengths of using digital platforms}

The postgraduate mathematics education students indicated that there were strengths in using digital platforms for the learning of mathematics. Their sentiments are presented in the subsequent subthemes.

\section{Experiences of using WhatsApp discussion forums}

The majority of the participants had positive experiences of using WhatsApp for the discussion forums as reflected in their discussion forum excerpts.

Anne: ...was easy and quick...convenient to respond...

Kavir: ...no problems with WhatsApp...could get quick feedback...easy to go back and see what I missed...I work on my own first...then I can discuss my answers... also each to ask the group for maths resources...group gave ideas on how to give feedback in algebra...

Lungi: ...easy to use WhatsApp...use it all the time with my family and friends...also could chat quickly about other stuff...not only maths...

Nancy: ...WhatsApp is easier to use than Moodle...could quickly look at what I missed and follow the conversation...the lecturer responded quickly to help us... also a good way to keep in touch with each other...

Based on the evidence, the participants agreed that WhatsApp assisted in providing immediate feedback and offered a means of communicating instant social messages. These participants were participating interactively within their virtual COP using digital platforms. The sharing of mathematics worksheets and resources was easy and quick to distribute to the virtual COP using WhatsApp. This engagement via digital platforms is important for enhancing academic success and development in mathematics within the era of the $4 \mathrm{IR}$.

\section{Digital platforms provide unlimited access to module material and resources}

The participants valued the notion of creating a mathematics repository, uploading videos, resources and recordings of the workshops and discussion forums as reflected in the excerpts that follow.

Nancy: ...recordings and videos were easy to view at any time...this helped me...I could revisit the workshops at any time...clarify my answers...had time to think about what I was learning...

Lungi: ...during the lockdown...difficult to concentrate...had to see to my family...at night I could look at the workshop videos...help me understand and catch up... could think...I even learnt about other misconceptions learners have in geometry...

Nomsa: ...needed time to think about what was discussed...I could look at the recordings after the workshop... helped me with understanding assessment methods better...worked on my task...then shared with the group...we discussed and shared our views...the lecturer gave us help if we needed it...other students also shared resources online...we developed an online maths data bank...

Siya: ...couldn't concentrate totally during the workshop... too many distractions at home. I could look at the video when I had quiet time to focus...this was useful...I could look back on what I learnt and think carefully about the maths...I could look at the videos at any time...the online maths data bank with examples and resources also helped me... 
Xolani: ...the uploaded content helped...I could learn at any time...the data bank we developed also assisted with checking misconceptions and providing feedback in maths...I could study anytime and anywhere I even could learn in my car..

As was evident, the majority of the participants appreciated the uploaded workshop videos and recordings. In addition, the virtual COP developed an online data bank with mathematics examples of assessing and providing feedback as well as resources on identifying misconceptions in geometry. These resources were valued by the participants and provided them with new learning experiences as they discovered, for example, other misconceptions that learners may acquire in geometry. They felt at ease that they could view the uploaded material at any time when it was suitable for them. It was evident that the participants were prepared to engage with online material. In addition, with the uploading of the online data bank developed by the virtual COP, the participants had access to mathematics support at any time. This is an important step for achieving academic success in mathematics within the era of the $4 \mathrm{IR}$.

\section{Support received within the digital community}

The virtual COP formed by using digital platforms created a support mechanism for the participants, as reflected in the subsequent excerpts.

Delani: ...felt belonged...the class cared about me...my child was sick...I could talk to the class on WhatsApp about what was going on at home... they helped me...gave me advice...told me about the drive-through COVID-19 testing places around me...

Leon: ...could use WhatsApp to find out how everyone was... if anyone was going through a bad time...we offered advice and help. Good to talk to people who knew what you were going through... better to use WhatsApp than Moodle...got replies almost instantly...could also check up on each other...the group helped me complete the algebra question...

Patrick: ...when we had problems...helped each other...got support from the group...it was good...I could submit my maths work with success...we created our own maths resource bank for the group...all shared our worksheets and examples that we use in our own class...

Thandi: ...the online group provided good help...not only about the maths work but also about family problems...

Based on the preceding excerpts, creating a supportive virtual COP was beneficial for the participants. They valued the online support they received concerning the mathematics being discussed as well as the online social support they received during the COVID-19 pandemic. The participants' willingness to embrace the online platforms and support other members of their COP while they learnt about mathematics academic writing, assessing and providing feedback in algebra and identifying learner misconceptions in geometry was encouraging. In addition, the development of the online repository with mathematics resources and mathematics examples supported active online interaction and engagement. This robust engagement and interaction via the Internet using digital platforms is supported within contemporary 4IR lecture rooms.

\section{Collaboration is encouraged within the digital community}

Collaboration and the sharing of ideas were essential to the participants, as reflected in the excerpts that follow.

Delani: ...worked well in the group...shared problem-solving and how to give feedback to learners...discussed answers...we placed examples in the data bank to help each other...the lecturer assisted and explained concepts further...it was good to belong to the online group... learnt new assessments methods from resources shared online...

Devi: ...discussed how to teach learners who had misunderstandings in geometry...shared advice about how to help learners with understanding geometry better...the group placed their examples in the online data bank. We helped each other as a group...could complete the task through this help...realised we needed to do our work on our own first and then discuss and share our answers..

John: ...if someone needed help we gave support. We looked at each other's answers first...then we gave advice about what worked for us in the class...we asked the lecturer to assist or we needed more explanation...could check on each other at any time using WhatsApp... working in the group was helpful..

Nomsa: ...no extra effort was required...convenient and was quick to respond to questions and share mathematics resources that work for us...got others' feedback quickly...I could also look at the data bank...I could complete my work with this help...

Patrick: ...some of us had the same problems...for example the geometry problems were confusing...we could share advice...shared resources online...we worked together...it was useful...helped each other...

To take advantage of 4IR opportunities, more so within the era of the COVID-19 pandemic, the lecturer in this study transformed pedagogy to include the use of technologybased tools and digital platforms. It was evident from the discussion forums that members of the virtual COP in this study engaged with each other online and shared resources and examples online using a data bank. For example, based on the evidence provided, if the participating postgraduate mathematics education students within the virtual COP needed further assistance when solving the mathematics problems under discussion, they sought help from the lecturer who was also a member of the virtual COP and shared resources with each online. These resources included examples of assessments in mathematics, how to provide feedback in mathematics as well as common misconceptions in geometry. These examples and resources were uploaded into a data bank created by the virtual COP. As was evident, while the participants mentioned that collaboration was of value when using digital platforms, they valued their interaction within their virtual COP. However, they also indicated that they experienced challenges when using 
digital platforms. These challenges are discussed in detail in the following section.

\section{Challenges of using digital platforms}

The participants indicated that there were challenges in using digital platforms for the learning of mathematics. Their views are presented in the subsequent subthemes.

\section{Need training to use digital platforms effectively}

The participants did not generally use Zoom and were only exposed to this digital platform during the COVID-19 pandemic. They needed to practise and prepare for using this digital platform as is reflected in the following discussion forum excerpts.

Devi: ...was difficult at first...got easier as I experimented and tried out Zoom ...I think we need enough training before using Zoom...

John: ...Zoom is something different...needed to learn how to work with Zoom...then only was I ok in the workshop... still had problems raising my hand...the buttons on the Zoom system changed....

Siya: ...the workshops were a bit difficult to follow...my Zoom link was not stable...wish we could have face-face workshops...needed to learn quickly how to use Zoom...

Xolani: ...had to learn how to use Zoom...I studied the guide... but still asked my friends and my child for help...I felt I was missing out...needed extra time to learn...

As was evident, Zoom workshops were a new form of learning for the participants. This new learning method required practice and collaborative engagement within the virtual COP for the participants to navigate this digital platform successfully. These participants exhibited characteristics of digital immigrants, and it was evident within this virtual COP that the 4IR impacts the purpose that higher education institutions play in preparing students for succeeding within a technologically advanced society. Also, during the period of the workshops, the Zoom platform and functions were revised to a minor extent; this resulted in the participants having to relearn and practise how to use specific revised techniques. This took place during the second workshop. As a result, considerable teaching and learning time was lost due to addressing technical issues during the second workshop.

\section{Devices, data and resources for working within digital platforms are expensive}

To use digital platforms, the participants required access to digital devices and data. Some participants experienced difficulties with this, as reflected in the following excerpts.

Kavir: ...I relied on the university Wi-Fi and computers... with COVID...was forced to work at home...this created lots of expenses...had to buy a second-hand laptop and data for Internet...

Lungi: ...the Zoom workshops took a lot of data...was expensive to use. I had to download information from the Internet...these free websites are not free...too costly.... a difficult time to make ends meet at home...no one else is working at home because of COVID...lucky for the free online data bank we created in the group... these resources helped me a lot...

Rani: ...the resources that we need is expensive to download...takes time to download...costs me a lot of data...lots of money...the online data bank worked well for me...

Thulani: ...I paid fees to study at the university...thought I would use the university library. With COVID...I am working at home...I don't have a computer...I am using my phone...also costs lots of money to work from home...did not think about this expense earlier on...did not budget for this...

Participants revealed that devices and data were expensive to purchase, especially as this was unforeseen at the beginning of the 2020 academic year. The participating university offers only the contact mode of learning under normal circumstances; however, due to the COVID-19 pandemic, the university was required to provide lectures online or remotely via the use of digital platforms. As was evident, it was important for lecturers to be aware of their students' challenges concerning the availability of technology-based tools to engage with digital platforms when learning. This knowledge supported the lecturer when presenting the notions of the 4IR within the education environment. Through engaging within the virtual COP, all members were made aware of challenges experienced by members within the COP. The creation of the online data bank supported students with examples and resources for mathematics. Since these were free mathematics resources, this was of benefit to the virtual COP during this challenging pandemic. Based on the evidence provided, both the participating postgraduate mathematics education students and the lecturer needed to adapt quickly to this new pedagogical approach to achieve success within the contemporary 4IR lecture context.

\section{Using digital platforms within the COVID-19 pandemic era is socially complex}

The COVID-19 pandemic era resulted in many people working from home with their families around them; this created difficulties for the participating postgraduate mathematics education students as captured in the following excerpts.

Lungi: ...my children with me at home...difficult to attend workshops with them...they are young and need me... found it hard to concentrate and take care of my children at the same time...

Nancy: ...live with my parents and my husband and small children...during COVID we are all at home in a tiny house...my husband does not understand that I need to work...have other work at home that I need to do first...was very stressful for me...my husband was complaining all the time...I could not cope...

Thandi: ...as a woman...lots of responsibilities at home... especially with COVID. Everyone is home...need to clean and cook and take care of my family...it was hard 
for me to attend online workshops and complete my other responsibilities...that is why I prefer to study from campus...

Thulani: ...no privacy at home...we are all at home in one house during lockdown...difficult for me to respond and ask questions in the workshops...everyone at home is listening to my workshop...

Xolani: ...my child is also studying....also has Zoom lectures... have a small house...need to plan so that we can have space to work...distracting when we have lectures at the same time...sometimes I sit in my car during the lectures...

Working and studying from home, especially during the COVID-19 lockdown conditions, created many challenges. Often family responsibilities needed to be addressed first before the participating postgraduate mathematics education students could start with academic work. As was evident, members of the virtual COP within this study experienced challenges attributed to the COVID-19 pandemic. Fortunately, the digital world has transformed education contexts that embrace notions of the 4IR. Teaching and learning were transformed using technology-based tools within the education context under study. The participating postgraduate mathematics education students and the lecturer did not have to engage within the virtual COP at the same time. Teaching and learning could occur successfully at any time using digital platforms. While members of the virtual COP within this study may not have been able to attend the online workshops, they were provided with the opportunity to view the uploaded content, workshops and videos at any time. In addition, the members of the COP could consult with the resources in the online repository if they needed more assistance. After that, the members of the virtual COP within this study could engage with other members of the online community through WhatsApp and the discussion forums on Moodle to seek further guidance and assistance.

\section{Using digital platforms for learning mathematics is time consuming and uncomfortable}

Learning how to use digital platforms was difficult and often took much time, as reflected in the following excerpts.

Anne: ...took long for me to log onto to Moodle and follow the conversation...also when I posted a question...it took long for me to get an answer...

Nancy: ...I used Moodle in my undergrad days...but uncomfortable to use. It is hard to follow the conversations since there are so many and everything is sent to your email...I am looking at emails and Moodle... need to catch up...

Nomsa:...waited long for the class to respond on Moodle...I needed help immediately...so I had to use WhatsApp to get help...this is when we started sharing maths resources with each other...this was useful...

Rani: ...Moodle is ok...but sometimes people take long to respond...need to wait until someone replies...it is limiting me...
Siya: ...it was tricky using Moodle...took time for me to find the conversation and then I did not know to reply...this wasted much time...

Xolani: ...had a problem accessing Moodle...forgot my password...needed to set up a new one...so I had to catch up with the discussion...was stressful...I felt I was left behind...lucky for the WhatsApp chats...kept me informed...

As was evident, the participants mentioned the challenges of using digital platforms. While the participants used Moodle previously, they did experience a few issues. When they needed a quick response, Moodle was tricky and uncomfortable to use and did not assist with providing rapid feedback. It was evident in this study that the participants needed to engage within their virtual COP for support and guidance with the mathematics problems under study. As a result, the participants used the digital platforms available to them to communicate and engage with other members of the virtual COP quickly and easily. In addition, the online repository with resources and examples that were developed by the COP was useful when the participants needed added support. Lecturers who embrace the notions of the 4IR ensure that their students have access to various technology-based tools and digital platforms to enhance and support teaching and learning within the era of the 4IR. To further interrogate the results and to exhibit the significance of this study, a comprehensive discussion is included in the following section.

\section{Discussion}

The qualitative results provide evidence of postgraduate mathematics education students' experiences of using digital platforms during the COVID-19 pandemic era for the learning of mathematics. Firstly, the participants generally experienced positive experiences of using WhatsApp chats; however, it was evident that they experienced difficulties when using Zoom and Moodle. Still, it is important to note the WhatsApp platform may create challenges for students when balancing online activities and academic planning, and may also distract students from finishing their assessments timeously (Mbukusa, 2018). However, based on the evidence, it was apparent within the virtual COP under focus that through collaboration and shared interest (Wenger, 1998), the participants managed to complete the mathematics academic writing, algebra and geometry tasks as discussed during workshops. Thus, these participants embraced the notions of a COP by focusing on sharing ideas and providing support to other online community members. The participating postgraduate mathematics education students within the virtual COP also developed an online repository with resources and examples that provided information regarding identifying learner misconceptions in geometry and assessing and providing feedback in algebra. This repository was available for any member of the virtual COP to access at any time. Thus, communication and the sharing and discussion of ideas is essential to mathematics pedagogy, and it is important for mathematics 
teachers to become actively involved in adding to the development of knowledge (Lazarus \& Roulet, 2013). In this study, the use of digital platforms allowed participants to engage within the virtual COP actively, and the community members shared ideas through individual and collaborative attempts (Mlotshwa \& Chigona, 2018; Osterholt \& Barratt, 2010). This was evident during the academic writing, algebra and geometry workshops, where the participants showed evidence of practising the mathematics tasks independently first to promote meaning and understanding. Only when the participants encountered challenges, did they seek assistance from the virtual COP via the discussion forums or WhatsApp. The discussion forums on Moodle and WhatsApp created an added layer of mathematics support for members of the virtual COP. Thus, WhatsApp is a novel teaching method that can appeal to students and provide them with prospects for further learning (Mbukusa, 2018). The actions of the participants in this study exhibit the fundamental elements of learning: practice, meaning, identity and community within a COP (Wenger, 1998). The participants shared experiences of good practice and discussed their own meaning-making of the resources that were shared in the online data bank. This sharing of ideas and resources created an empowered online community which helped shape the identity of each member of the virtual COP.

Similarly, Wenger and Wenger-Trayner (2015) proposed that members of a COP need to collaborate around ideas related to the content under study which was evident in this study. The participants showed evidence of networking with their virtual COP members to learn mathematics together. The participants also exhibited evidence of embracing notions of the 4IR by engaging with technologybased tools and digital platforms, in addition to developing an online repository to learn mathematics. Similarly, Ertmer and Ottenbreit-Leftwich (2012) suggested that the effective incorporation of technology-based tools within education contexts would support learning. In this study, mathematics learning was supported and enhanced using digital platforms.

Secondly, the participants indicated that the uploaded lectures, videos, recordings and online data bank were beneficial in that they could access information at any time. In this way, the participants were not compelled to engage with content, other members of the online COP and resources during a specific period and while they were in a certain location. This is important to consider since research (Jeffrey et al., 2014) has maintained that the use of online pedagogy disregards the confines of time, place and obstacles while empowering active collaboration between members within the COP under focus. Within the ambits of COP, collaboration is supported so that learning is enriched by sharing and discussion (Wenger, 1998; Wenger \& Wenger-Trayner, 2015). As was evident, in this study, the participants embraced the notions of the 4IR by using digital platforms. The participants collaborated and discussed solutions for the algebra and geometry tasks within the virtual mathematics COP. They further collaborated to develop an online repository for learning mathematics. The lecturer formed part of the virtual COP by presenting course content and guiding the learning process. It was evident that the implementation of digital platforms for learning mathematics fostered and developed supportive relationships within the virtual COP under focus (Mlotshwa \& Chigona, 2018).

Thirdly, while the participants mentioned that there were strengths in using digital platforms, they also indicated that they needed to practise and required training and time to prepare for using these digital platforms efficiently. They believed that practising using these platforms first before being expected to engage within these platforms formally (for example, the Zoom digital platform) would assist them in feeling more comfortable with participating in the online workshops. Moreover, the idea of practising using the online platforms would support and equip students to engage with each other and the content being discussed. Similarly, research (Thieman, 2008) maintains that for students to achieve success with digital pedagogy, they need to be prepared adequately since the use of technology within the 4IR education context is important (Boholano, 2017). Students need to know the nuances of the online class and what is expected of them within the online course. To assist with achieving preparedness in this respect, an orientation session needs to be included before engaging with online pedagogy (Mensch, 2017).

Fourthly, in this study, it was evident that limited access to digital devices and data for the Internet influenced the participants' use of online learning and digital platforms (Klopfer et al., 2006). The participants believed that they need to have the basic requirements for digital pedagogy (for example, digital devices and access to data and the Internet) to achieve success with digital learning. Furthermore, postgraduate mathematics education students indicated that the virtual COP fostered active interaction and supported the acquisition of new knowledge using various digital platforms. This result resonates with research by Jeffrey et al. (2014), which maintained that students need to be encouraged to reflect on their learning so that they are provided with diverse new learning experiences and resources. As was evident in this research, using digital platforms, the participants were encouraged to become responsible for their mathematics learning. For example, members of the virtual COP within this study came up with the idea of sharing mathematics resources online to support their learning of mathematics. This idea escalated into the creation of an online mathematics data bank. This showed evidence of the participants independently taking responsibility for their own mathematics learning. This independence promoted their ability to learn mathematics at any time and place. Similarly, linking students and online platforms does not necessarily take place in a physical education context; this is ubiquitous due to their access to the Internet (Bell, 2011). Also, to promote student success within the 4IR, education 
institutions need to adjust traditional pedagogy to prepare students suitably (Butler-Adam, 2018).

Finally, the challenge of working from home during the COVID-19 pandemic area was also a significant difficulty. It led to many social and academic issues for these participating postgraduate mathematics education students. The advantages of collaboration and communication offered by using digital platforms within the context of COVID-19 was significant. Lecturers need to note that students are sociable people and require feedback and support from peers and the lecturer during these extraordinary circumstances. Apart from communication about the specific challenges concerning the learning of mathematics being discussed, during lockdown conditions within the COVID-19 pandemic, students may not have other people who may relate to what they are experiencing within their contexts. A virtual COP builds feelings of trust and camaraderie, and supports the online community in curbing the perception of social isolation (Schieffer, 2016). Thus, for emotional, health and social benefits, students need to discuss and interact with their peers and lecturer during this unprecedented era.

\section{Conclusion}

This study was conducted to respond to the question: what are postgraduate mathematics education students' experiences of using digital platforms for learning within the COVID-19 pandemic era? The article concludes with possible suggestions for lecturers who wish to use digital platforms for the learning of mathematics. These suggestions are based on the experiences of the participants as uncovered in this study.

Firstly, the difficulties of using digital platforms within the era of COVID-19 are vital for lecturers to note. To alleviate this issue, it is important for the lecturer to ensure that students have access to digital devices and data for using the Internet. Lecturers need to establish that the resources being used are easy to use, readily available, inexpensive and data efficient. Also, students need to be provided with orientation sessions on the use of digital platforms to better prepare them for using these platforms effectively and successfully.

Secondly, the challenges experienced by the participants in this study are important to note. The participants indicated that they needed space and time to practise and engage with the online mathematics examples first before interacting within the online community. Lecturers need to consider providing students with the content and material for discussion in advance of the online lecture or workshop. This allows students to study the content independently first. Also, the participants in this study valued the collaborative online discussions, which, for example, focused on identifying learner misconceptions in geometry. The participants reflected on and discussed their experiences with their virtual COP, and through this reflection on experiences, collaborative ideas revolving around teaching to avoid misconceptions in geometry were circulated online. Also, the participants shared examples and resources for assessing algebra, providing feedback in algebra and identifying learner misconceptions in geometry with their virtual COP. Through this sharing of ideas and resources, the participants developed an online mathematics data bank for identifying learner misconceptions in geometry and assessing and offering feedback in algebra to mathematics learners. This online mathematics data bank was available on Moodle and was available for any participant within the virtual COP. Thus, as we embrace the 4IR and as we engage within digital platforms, lecturers need to create a similar virtual COP to engage with each other to develop data banks and repositories to support mathematics teachers. These online repositories provide an added layer of support to address mathematics teaching and learning challenges, and due to the nature of digital platforms, these online repositories and data banks are accessible at any time.

Thirdly, when preparing for online pedagogy during COVID-19 pandemic conditions, lecturers need to acknowledge that students have family responsibilities to deal with during these extraordinary circumstances. Lecturers need to recognise that students are sociable people and need support, encouragement and feedback from other members of the online community. The advantages of the collaboration inspired by using digital platforms within the era of the pandemic are significant. Students may need to use these digital platforms for social and emotional support during this unprecedented time to deal with family and academic issues.

Finally, this study is not without limitations. The study was located at one teacher education context during the COVID-19 pandemic era. It was conducted to explore postgraduate mathematics education students' experiences of using digital platforms for learning within the COVID-19 pandemic era. Due to the importance of the study, further systematic studies based on other teacher education institutions nationally and globally could complement and provide additional insights on the topic. New empirical research could also test the strength of the research process and instruments. New empirical research may also assist in determining further noteworthy experiences of postgraduate mathematics education students on the use of digital platforms for the learning of mathematics. The experiences of postgraduate mathematics education students, as discussed in this article, focuses on their use of digital platforms for learning within the COVID-19 pandemic era. The implications, results and limitations as discussed in this article add new knowledge to the field. Also, this new knowledge is of benefit to lecturers globally as we embrace the use of digital platforms for the learning of mathematics, especially within the context of the COVID-19 pandemic era. 


\section{Acknowledgements Competing interests}

The author declares that she has no conflicting interests that may have inappropriately influenced her in writing this article.

\section{Authors' contributions}

The author declares that she is the sole author of this article.

\section{Funding information}

The author is thankful to the National Research Foundation (NRF), who partially funded this research (grant number: TTK170408226284, UID: 113952).

\section{Data availability statement}

Data sharing is available on request.

\section{Disclaimer}

The views expressed in this submitted article are those of the author and do not reflect the official position of the institution or funder.

\section{References}

Bell, F. (2011). Connectivism: Its place in theory-informed research and innovation in technology-enabled learning. The International Review of Research in Open and Distributed Learning, 12(3), 98-118. https://doi.org/10.19173/irrodl.v12i3.902

Boholano, H.B. (2017). Smart social networking: 21st century teaching and learning skills. Research in Pedagogy, 7(1), 21-29. https://doi.org/10.17810/2015.45

Bruce, C.D. (2012). Technology in the mathematics classroom: Harnessing the learning potential of interactive whiteboards. What works? Research into Practice, 38 (March), 1-4. Available from http://www.edu.gov.on.ca/eng/literacynumeracy/ inspire/research/WW_technology.pdf

Butler-Adam, J. (2018). The Fourth Industrial Revolution and education. South African Journal of Science, 114(5), 1. https://doi.org/10.17159/sajs.2018/a0271

Buzzard, C., Crittenden, V.L., Crittenden, W.F., \& McCarty, P. (2011). The use of digital technologies in the classroom: A teaching and learning perspective. Journal of Marketing Education, 33(2), 131-139. https://doi.org/10.1177/ 0273475311410845

Cheung, A.C.K., \& Slavin, R.E. (2013). The effectiveness of educational technology applications for enhancing mathematics achievement in K-12 classrooms: A metaanalysis Educational Research Review, 9(1), 88-113. https://doi.org/10.1016/j. edurev.2013.01.001

Drijvers, P. (2013). Digital technology in mathematics education: Why it works (or doesn't). Revista de Investigación en Didáctica de la Matemática, 8(1), 1-20. https://doi.org/10.1007/978-3-319-17187-6_8

Dubé, L., Bourhis, A., \& Jacob, R. (2006). Towards a typology of virtual communities of practice. Interdisciplinary Journal of Information, Knowledge, and Management, 1(1), 69-93. https://doi.org/10.28945/115

Ertmer, P.A., \& Ottenbreit-Leftwich, A. (2012). Removing obstacles to the pedagogical changes required by Jonassen's vision of authentic technology-enabled learning. Computers \& Education, 64(1), 175-182. https://doi.org/10.1016/j. compedu.2012.10.008

Goertz, P. (2015). 10 Signs of a 21st century classroom. Nicasio, CA: George Lucas Educational Foundation.

Grand-Clement, S., Devaux, A., Belanger, J., \& Manville, C. (2017). Digital learning Education and skills in the digital age. Cambridge. https://doi.org/10.7249/CF369

Graven, M., \& Lerman, S. (2003). Book review: Wenger, E. (1998). Communities of practice: Learning, meaning and identity. Journal of Mathematics Teacher Education, 6(1), 185-194. https://doi.org/10.1023/A:1023947624004
Handayanto, A., Supandi, S., \& Ariyanto, L. (2018). Teaching using moodle in mathematics education. Journal of Physics: Conference Series, 1013(012128), 1-4. mathematics education. Journal of Physics: Conference
https://doi.org/10.1088/1742-6596/1013/1/012128

Hearn, S., \& White, N. (2009). Communities of practice: Linking knowledge, policy and practice. Background Note (pp. 1-4). London: Overseas Development Institute.

Helsper, E., \& Enyon, R. (2009). Digital natives: Where is the evidence? British Educational Research Journal, 36(3), 1-18. https://doi.org/10.1080/01411920902989227

Jayashree, T., \& Tiwari, S. (2016). Usefulness and practicality of Moodle quizzes to enhance the learning process for foundation mathematics courses in engineering (pp.1-8).Retrievedfromhttps://assets.moodlemoot.org/sites/85/20181207062309/ Usefulness-and-practicality-of-Moodle-quizzes-to-enhance-the-learning-processfor-Foundation-Mathematics-courses-in-Engineering.pdf

Jeffrey, L.M., Milne, J., Suddaby, G., \& Higgins, A. (2014). Blended learning: How teachers balance the blend of online and classroom components. Journal of Information Technology Education: Research, 13(1), 121-140. https://doi. org/10.28945/1968

Klopfer, E., Osterweil, S., Groff, J., \& Haas, J. (2006). Using the technology of today, in the classroom today. The instructional power of digital games social networking simulations and how teachers can leverage them. Cambridge, MA: The Education Arcade.

Lazarus, J., \& Roulet, G. (2013). Creating a YouTube-like collaborative environment in mathematics: Integrating animated GeoGebra constructions and studentgenerated screencast videos. European Journal of Contemporary Education, 4(2), 117-128. https://doi.org/10.13187/ejced.2013.4.117

Lopes, A.P., Babo, M., \& Azevedo, J. (2008). Teaching and learning mathematics using Moodle. Paper presented at the 2nd International Technology, Education and Development Conference (INTED 2008), 3-5 March 2008 (pp. 1-9). Valencia: International Association of Technology, Education and Development.

Mbukusa, N.R. (2018). Perceptions of students' on the use of WhatsApp in teaching methods of English as a second language at the University of Namibia. Journal of Curriculum and Teaching, 7(2), 112-119. https://doi.org/10.5430/jct.v7n2p112

Mensch, S. (2017). Improving distance education through student online orientation classes. Global Education Journal, 1(1), 1-6.

Mlotshwa, N., \& Chigona, A. (2018). Using Moodle to enhance Mathematics learning in Grade 10 classrooms in South Africa. Paper presented at the E-Learn 2018 Conference, Las Vegas. Retrieved from http://digitalknowledge.cput.ac.za/ bitstream/11189/6936/1/Mlotshwa_N_Chigona_A_Edu_2018.pdf

Montrieux, H., Vanderlinde, R., Schellens, T., \& De Marez, L. (2015). Teaching and learning with mobile technology: A qualitative explorative study about the introduction of tablet devices in secondary education. PLoS One, 10(12), 1-11. https://doi.org/10.1371/journal.pone.0144008

Murgatrotd, S. (2020). COVID-19 and online learning. Retrieved from https://www. researchgate.net/publication/339784057_COVID-19_and_Online_Learning

Osterholt, D.A., \& Barratt, K. (2010). Ideas for practice: A collaborative look to the classroom. Journal of Developmental Education, 34(2), 26-35.

Peachey, N. (2017). Digital tools for teachers. Kent: PeacheyPublications.Com.

Pope, S., \& Mayorga, P. (2019). Enriching mathematics in the primary curriculum. Exploring the Primary Curriculum. London: Sage.

Qurat-ul, A., Farah, S., Muhammad, A., Muhammad, A.I., Muhammad, A.I., \& Muhammad, M.Y. (2019). A review of technological tools in teaching and learning computer science. Eurasia Journal of Mathematics, Science and Technology Education, 15(11), 1-17. https://doi.org/10.29333/ejmste/109611

Sahal, M., \& Ozdemir, A.S. (2020). Pre-service primary teachers' views and use of technology in mathematics lessons. Research in Learning Technology, 28(1), 1-17. https://doi.org/10.25304/rlt.v28.2302

Schieffer, L. (2016). The benefits and barriers of virtual collaboration among online adjuncts. Journal of Instructional Research, 5(1), 109-124. https://doi. org/10.9743/JIR.2016.11

Schuck, S. (2016). Enhancing teacher education in primary mathematics with mobile technologies. Australian Journal of Teacher Education, 41(3), 125-139. https:// doi.org/10.14221/ajte.2016v41n3.8

Schwab, K. (2016). The Fourth Industrial Revolution (pp. 172). Geneva: World Economic Forum.

Stols, G., Ferreira, R., Pelser, A., Olivier, W.A., Van De Merwe, A., De Villers, C., \& Venter, S. (2015). Perceptions and needs of South African Mathematics teachers concerning their use of technology for instruction. South African Journal of Education, 35(4), 1-13. https://doi.org/10.15700/saje.v35n4a1209

Thieman, G.Y. (2008). Using technology as a tool for learning and developing 21st century citizenship skills: An examination of the NETS and technology use by preservice teachers with their K-12 students. Contemporary Issues in Technology and Teacher Education, 8(4), 342-366.

Wenger, E. (1998). Communities of practice. Learning as a social system. Systems Thinker, 9(5), 1-10. https://doi.org/10.1017/CBO9780511803932

Wenger, E., \& Wenger-Trayner, B. (2015). Communities of practice: A brief introduction Retrieved from https://wenger-trayner.com/introduction-to-communities-ofpractice/ 